\title{
A "scorpion fish" (Trachinus vipera) sting: fishermen's hazard
}

\author{
Avi Dehaan, Patrick Ben-Meir, Amiram Sagi
}

\begin{abstract}
"Scorpion fish" is a nickname given by fishermen to members of the Trachinidae family as a result of their unusual stinging mechanism. These fish are found throughout the eastern Atlantic region from the North Sea through the Mediterranean and Black Seas and along the western coast of Northern and Central Africa. They are characterised by poisonous glands located at the base and sides of the spines of their anterior back fin and at the base of a spine located on the gill cover (fig 1). Because of the unusual location of the glands, fishermen handling these fish frequently suffer local injuries. A case of necrosis of the tip of the middle finger after a "scorpion fish" sting is described.
\end{abstract}

\section{Case report}

A 65 year old fisherman was brought to the emergency room after a fish sting to his right middle finger. He complained of general weakness, headache, palpitations, and nausea. The injured finger had been immersed in ice water and was extremely painful. The fisherman brought the offensive fish with him and this was subsequently identified as Trachinus vipera, commonly known as the "scorpion fish".

On physical examination the finger appeared red and swollen; these signs gradually progressed to his forearm and arm. The results of laboratory tests and electrocardiogram were normal. The patient was treated with analgesics, antihistamines, and a prophylactic antibiotic (cephalosporin). Within the next 24 hours, the flare and swelling of the arm and forearm disappeared and were limited to the injured finger. Four days later a necrotic area, limited to the tip of the finger, appeared (fig 2).

The finger healed uneventfully once the area was left undisturbed for secondary healing and after

Department of Plastic Surgery, Soroka University Hospital and Faculty of Health Sciences, BenGurion University of the Negev, Beer-Sheva, Israel A Dehaan, P Ben-Meir, A Sagi sloughing of the necrotic tissue. Physiotherapy was started to combat stiffness in both joints of the finger. Six weeks after the injury the patient returned to his occupation (fig 3).

\section{Discussion}

The "scorpion fish"-Trachinus vipera-is the smallest member of the Trachinidae family, which includes three other species: Trachinus radiatus, Trachinus araneus, and Trachinus draco.$^{123}$ Their size varies from $15 \mathrm{~cm}$ ( $T$ vipera) to $45 \mathrm{~cm}$ ( $T$ draco). Due to their small size and poisonous potential, they do not have commercial value although they are considered to be tasty in several European countries. The body of the fish is brown with black stains, and is long and compressed at the sides. The back fin is divided into a short anterior fin containing the poisonous mechanism and a long posterior fin. Being seabed dwellers, they tend to bury themselves in sandy areas from which only their eyes and anterior back fins protrude. The mouth points upwards ready to entrap passing prey. The anterior back fin is black and serves as a warning device as well as a protective

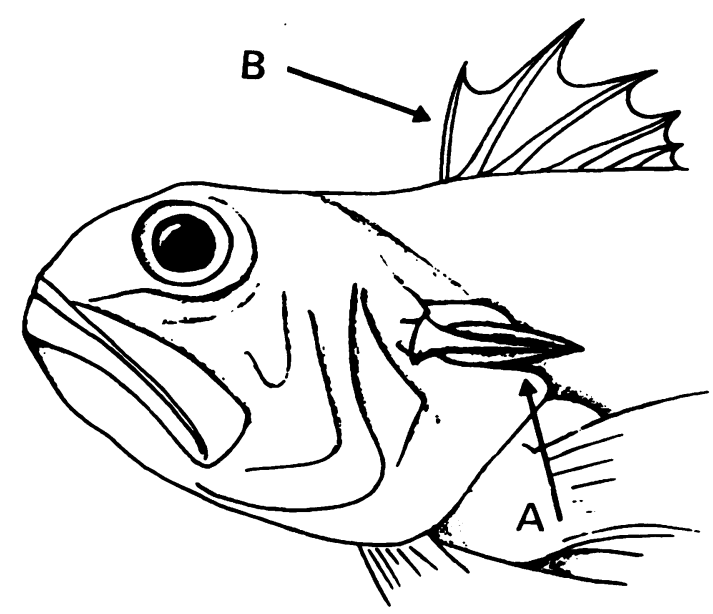

Figure 1 Localisation of the poisonous mechanism: (A) anterior back fin; (B) at the base of the spine located on the gill cover. 

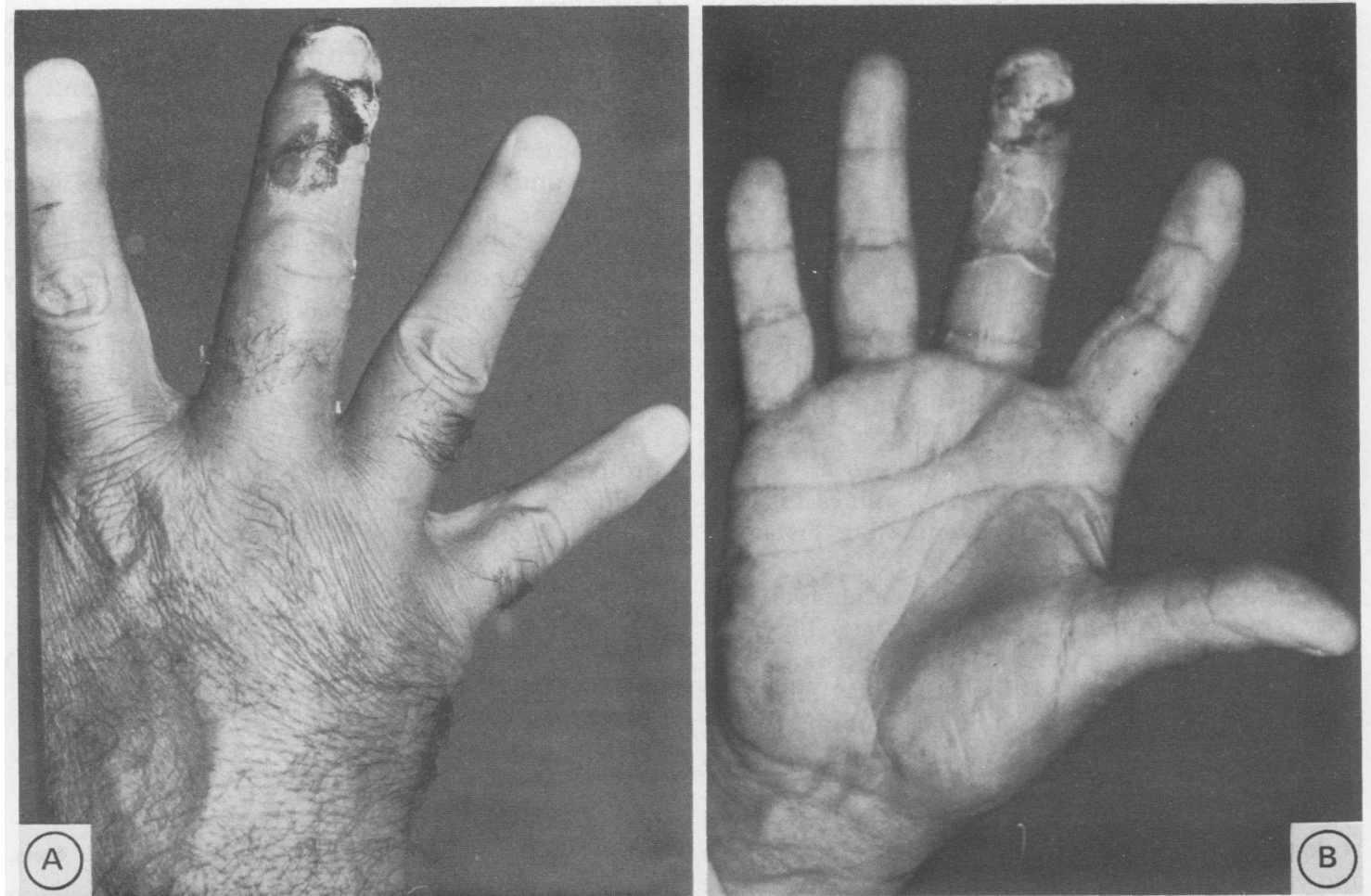

Figure 2 ( $A$ and $B$ ) The initial necrosis on both sides of the middle finger one week after injury.
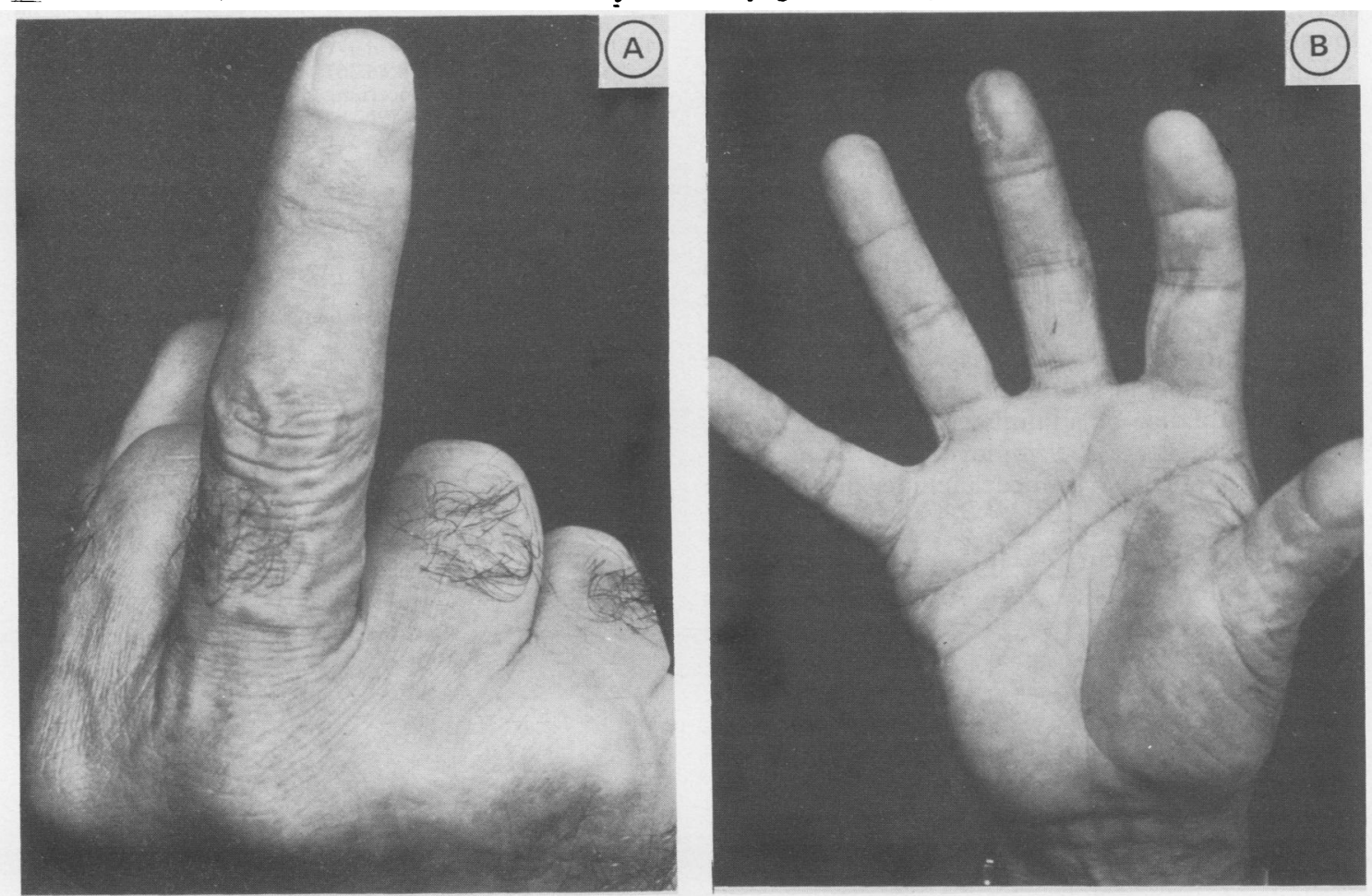

Figure 3 ( $A$ and $B) \quad$ The finger after secondary healing of the necrotic area.

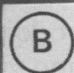


organ. ${ }^{12}$ This fin usually points backwards, but once the fish is caught, the spines on the fin straighten ready to sting the offender. As well as the vulnerability of fishermen, swimmers and waders are also in danger of being attacked. ${ }^{4}$

The venom is a clear grey fluid which has an ammoniacal odour. ${ }^{2}$ The median lethal dose $\left(\mathrm{LD}_{50}\right)$ for mice weighing $17 \mathrm{~g}$ was $0.0004 \mathrm{ml} .{ }^{56}$ The venom of $T$ vipera contains 5 -hydroxytryptamine, which produces the characteristic pain, and a protein responsible for the release of histamine, which produces the typical weal and redness. The venom also contains a mucopolysaccharide and albumin that do not generate a heparin-like reaction as is sometimes effected by other venoms. ${ }^{7}$ The $T$ draco venom contains large amounts of catecholamines together with a proteinacous fraction containing histamine and cholinesterase activity. ${ }^{8}$

Clinically, the injury first appears either as one dot or two dots about half a centimetre apart. The most striking clinical symptom is the intense pain accompanied by redness and swelling that may affect the whole limb. ${ }^{379}$ One victim attempted amputation of the involved fingers to terminate the pain. The pain may even cause syncope.

General symptoms include headache, chest and abdominal pain, fever, chills and sweating, nausea and vomiting, palpitations, bradycardia, appreciable psychic depression, respiratory distress, convulsions, and even death. Local necrosis may appear at the site of penetration of the venom.

Emergency treatment should include cleaning the affected area to remove remnants of the venom and heating of the affected area to the highest tolerable temperature. This may be effected by immersing the organ in hot water or by using any other heating device for a minimum of 60 to 90 minutes. The objective of this treatment is to destroy the venom and thus to abrogate its effect. ${ }^{310}{ }^{11}$ On arrival at the hospital, the administration of heat should be continued. Magnesium sulphate may be added to the bathing solution to soothe the affected area. Analgesics should also be administered or alternatively, local anaesthesia may be employed. ${ }^{4}$

Other supportive treatment includes prophylactic wide spectrum antibiotics and an antitetanus booster. Steroids should be given in cases of anaphylactic shock. Antihistamines have not been found to ameliorate the condition. ${ }^{10}$

In the described case, the affected area had not been cleaned and the finger had been immersed in ice water during the journey to the hospital. Appropriate treatment-that is, cleaning and heating of the finger-would probably have reduced the pain and may even have prevented the necrosis.

In summary, a typical case of a "scorpion fish" ( $T$ vipera) sting to a finger is described. This sting should be considered as one of the professional risks encountered by fishermen who are unaware of the special protective mechanism of the fish. Treatment must include thorough cleaning of the wound and heating of the affected area to the highest tolerable temperature.

Requests for reprints to: Dr Avi Dehaan, Department of Plastic Surgery, Soroka Medical Centre, PO Box 151, Beer-Sheva 84101, Israel.

1 Dor M. Zoological lexicon, vertebrata. Tel-Aviv; Dvir Press, 1975:95.

2 Halstead BW. Poisonous and alpha-venomous marine animals of the world. Princeton: Darwin Press, 1978:715.

3 Russell FE. Marine toxins and venomous and poisonous marine animals. New York: Academic Press, 1965:122.

4 Eliras A, Botwin S, Von-der-Walde I, Naor B. Poisonous fish stings. Harefuah 1974;86:367.

5 Skeie E. Problems concerning the poisonous Weever fish in Denmark. Nord Med 1962;67:429-34.

6 Skeie E. Toxin of the Weever fish (Trachinus draco): experimental studies on animals. Acta Pharmacologica Toxicologica 1962;19:107-20.

7 Carlisle DB. On the venom of the lesser Weeverfish-Trachinus vipera. Journal of the Marine Biology Association of the United Kingdom 1962;42:155-62.

8 Haavaldsen R, Funnum F. Weever venom. Nature 1963; 199:287.

9 Shafnir E. Trachinidae-Poisonous fish of the Mediterranean. Harefuah 1981;100:185.

10 Evans HM. Stingfish and seafarer. London: Faber and Faber, 1943:180.

11 Russell FE, Barritt WC, Fairchild MD. Electrocardiographic patterns evoked by venom of the Stingray. Proc Soc Exp Biol Med 1957;96:634.

Accepted 18 February 1991 